\title{
Chapter 20 \\ Seismic Hazard and Seismic Design \\ and Safety Aspects of Large Dam Projects
}

\author{
Martin Wieland
}

\begin{abstract}
Earthquakes can affect large dam projects in many different ways. Usually, design engineers are focussing on ground shaking and neglect the other aspects. The May 12, 2008 Wenchuan earthquake has damaged 1803 dams and reservoirs. The widespread mass movements have caused substantial damage to dams and surface powerhouses in Sichuan province in China. The different features of the earthquake hazard are presented, the most important are ground shaking, faulting and mass movements. The basic requirement of any large dam is safety. Today, an integral dam safety concept is used, which includes (i) structural safety, (ii) dam safety monitoring, (iii) operational safety and maintenance, and (iv) emergency planning. The importance of these four safety elements is discussed. The long-term safety includes, first, the analysis of all hazards affecting the project, i.e. hazards from the natural environment, hazards from the man-made environment and project-specific and site-specific hazards. The role of the earthquake hazard on the seismic design and seismic safety of large dam projects are discussed as, today, the structural safety of large storage dams is often governed by the earthquake load case. The seismic design and performance criteria of dams and safety-relevant elements such as spillways and bottom outlets recommended by the seismic committee of the International Commission on Large Dams are presented. The conceptual and constructional requirements for the seismic design of concrete and embankment dams are given, which often are more important than the seismic design criteria that are used as a basis for dynamic analyses. Finally, the need and importance of periodic reviews of the seismic safety of existing dams is discussed.
\end{abstract}

M. Wieland ( $\triangle)$

Committee on Seismic Aspects of Dam Design, International Commission on Large Dams, c/o Poyry Switzerland Ltd., Zurich, Switzerland

e-mail: martin.wieland@poyry.com 


\subsection{Introduction}

Because strong earthquakes occur very seldom in Central Europe, hardly any dam engineer or dam owner has any experience with earthquakes. It is also very hard to find any dams which have been damaged during earthquakes, although the average age of dams in Europe is around 50 years, and the total number of years of exposure of large dams to seismic action has been very large.

However, as strong earthquakes may affect a large area, many dams may be subjected to strong ground shaking as in the case of the May 12, 2008 Wenchuan earthquake in China, where about 1,803 dams and reservoirs, most of them were small earth dams, and 403 hydropower plants were damaged, four dams had a height exceeding $100 \mathrm{~m}$ (Wieland and Chen 2009). Also, during the 2001 Bhuj earthquake in Gujarat, India, 245 dams - mainly small embankment dams - had to be rehabilitated or strengthened after the earthquake. The latest earthquake which affected many dams was the March 11, 2011 Tohoku earthquake in Japan where on $18 \mathrm{~m}$ high embankment dam failed and 8 people lost their live. Another 400 dams, subjected to earthquake shaking, had to be inspected.

These examples show that earthquake safety needs proper attention. Also, the field of seismic hazard analysis has developed very fast in the last years, and the estimated seismic hazard has been increasing steadily. In addition, the seismic design and performance criteria and methods of seismic analysis have developed but at a much slower pace than the seismic hazard analysis methods.

As most existing dams built before the 1990s were designed against earthquakes using either seismic design criteria and/or methods of dynamic analysis, which are considered obsolete or even wrong today, the earthquake safety of these dams is not known if modern criteria are applied. It has to be assumed that a few of them are structurally deficient. Consequently, there is a need for the systematic reassessment of the earthquake safety of large and also small dams (Wieland 2003, 2006).

The paper gives an overview on the current state of the seismic design and safety aspects of large dams and the role of the earthquake hazard within the comprehensive dam safety framework that should be used for large dams. The subjects presented were addressed by the Committee on Seismic Aspects of Dam Design of the International Commission on Large Dams (ICOLD) in recent years or are direct consequences of guidelines published by ICOLD's seismic committee. The paper also summarizes the main subjects of the papers given in the list of references and provides general guidelines for the seismic safety assessment and design of large storage dams. 


\subsection{Dam Safety}

\subsubsection{Integral Dam Safety Concept}

The two main goals of every safety concept are the minimisation of all risks, and the mastering of the remaining risk in the best possible way. To reach these goals a comprehensive safety concept is used for large storage dams, which includes the following key elements (Wieland and Mueller 2009):

(i) structural safety (main elements: geologic, hydraulic and seismic design criteria; design criteria and methods of analysis may have to be updated when new data are available or new guidelines, regulations or codes are introduced);

(ii) dam safety monitoring (main elements: dam instrumentation, periodic safety assessments by dam experts, etc.);

(iii) operational safety (main elements: reliable rule curves for reservoir operation under normal and extraordinary (hydrological) conditions, training of personnel, dam maintenance, sediment flushing, engineering back-up. The most important element for a long service life is maintenance of all structures and components);

(iv) emergency planning (main elements: emergency action plans, inundation maps, water alarm systems, evacuation plans, etc.).

Therefore, as long as the proper implementation of these safety issues can be guaranteed according to this integral safety concept, a dam can be considered as safe.

Periodic safety assessments are indispensable as they will show what measures have to be taken to maintain or improve the safety and thus to even extend the lifespan. Deficiencies observed after commissioning must be rectified as early as possible.

\subsubsection{Structural Safety}

Structural safety is the main prerequisite for the safe operation of a storage facility and thus for its sustainability (Wieland 2012b). The basis for structural safety is laid mainly during design, as given by the design criteria. It is important that in the structural design all hazards, which can affect the dam are taken into account. The hazards are from the natural environment or are man-made. Furthermore, there are site and project related hazards (e.g. geology, hydro-geology, topography, vulnerability of dams to specific hazards etc.).

The design must be carried out assuming that the dam may become exposed to the worst possible scenario during a natural hazardous event, i.e. mainly floods and earthquakes. 
Older dams are often not designed according to today's design standards or guidelines. One reason is that since their conception more data have become available, which allow a more realistic prediction of extreme events. Such storage projects may have inadequate spillway capacity or the dam structures were designed with inadequate seismic loading.

Inadequate spillway capacity can be handled by constructing an additional spillway, or where feasible, by rising the dam crest.

The most severe loading for dam structures originating from the natural environment is caused by strong earthquakes close to a dam. Since the 1930s concrete and embankment dams were generally designed against earthquakes in most parts of the world. The earthquake loading was represented by a seismic coefficient, which was used in a pseudo-static analysis. In general a seismic coefficient of 0.1 was assumed almost irrespective of the seismic hazard at the dam site. Using this concept, the earthquake load combination was usually not the governing one in dam design.

Field observations and seismic hazard analyses, however have shown that even in regions of moderate seismicity, such as Central Europe, earthquakes with magnitudes up to $\mathrm{M}=6.5$ are possible, although with a very low probability of occurrence. Such earthquakes can cause much higher peak ground acceleration than those assumed for the dam design.

Modern seismic design criteria were published by ICOLD in 1989 which were revised in 2010 (ICOLD 2014). These design criteria are different from those used for dams built before 1989. Therefore, dams designed with a pseudo-static analysis method and a seismic coefficient may not satisfy today's seismic safety criteria and it has to be assumed that some of these dams are structurally deficient. Only an earthquake analysis can show if an existing dam is safe. Of course, this also applies to dams, which have not been designed against earthquakes.

This change in seismic design concept shows clearly that a dam, which was safe at the time of completion and which has satisfied all safety criteria, does not necessarily remain safe forever even if it is kept in excellent condition.

\subsubsection{Dam Safety Monitoring}

Dam safety monitoring is a key activity in dam safety management and includes the following activities:

(i) Visual inspection of the entire dam and its appurtenances. It also includes checking the functioning of the flood control elements, i.e. spillway gates and the valves or gates for the bottom outlets, and the emergency power supply.

(ii) Measurements of physical quantities (mainly deformations, pressures, flow/ seepage volumes, temperature, etc.) describing the status of the dam and its foundation. The measurements depend on the type of the dam and the local conditions. 
Monitoring provides a rational insight into the safety of the dam-foundation system. With modern automatic data acquisition systems real-time monitoring becomes possible and rapidly changing conditions can be recorded.

Instrumental monitoring, if systematically performed, can detect a developing deficiency at an early stage, however, only at locations where corresponding instruments have been installed, e.g. piezometers, seepage weir, settlement point, etc. In other locations only visual inspection can detect whether something is wrong or unusual.

Unfortunately, there are still many older dams, which have inadequate monitoring facilities. Even today, some dam owners are reluctant to install instruments in their new dams if this is not required by the authorities.

Instrumental monitoring also requires a strict data management and a graphical display of the measurements to enable the rapid identification of irregularities caused by deficiencies or also by faulty measurements or deficient equipment. An important concept in monitoring is redundancy.

Dam safety monitoring is the main element of dam safety management, which includes the following (Swiss practice):

(i) dam safety monitoring and regular visual inspections by the dam owner,

(ii) annual dam safety inspection by a dam engineer, and

(iii) detailed dam safety inspection every 5 years by an independent dam engineer and a geologist. During the 5-year-inspection changes in the safety and design criteria, and new information on hazards affecting the dam are reviewed as well. If important changes have been observed a new safety check will be needed. In the past the safety checks included mainly the flood and earthquake safety.

During operation of the dam a dam safety authority should supervise the surveillance organisation of the owner, of the experienced engineer and of the experts.

If a dam does not comply with current dam safety standards or shows unusual behaviour, the most effective mean for reducing the risk is a reduction of the reservoir level.

\subsubsection{Operational Safety}

The importance of operational safety of dams is sometimes overlooked. In the case of hydropower plants it includes the following: Operational guidelines for the reservoir for usual, unusual and extreme conditions; training of personnel; experienced and technically qualified dam maintenance staff; dam maintenance procedures; engineering back-up to cope with unusual behaviour of the dam, etc.

Maintenance is the key issue as it is the prerequisite for long-term safety. If a dam designed for say 100 years is not maintained it can become unsafe within a very short period of time especially if the spillway gates and bottom outlets and the dam monitoring systems are no longer functioning properly. 


\subsubsection{Emergency Planning}

The main risk for embankment dams is overtopping during large floods. Hence, upgrading of spillways with inadequate discharge capacity will reduce this risk in embankment dams.

In addition, storage dams should be provided with a bottom outlet, such that the reservoir can be drawn down to a safe level in an emergency situation, especially after a strong earthquake when parts of the dam may be damaged. This would require that the discharge capacity of the bottom outlet and other low level outlets must be larger than the average inflow into the reservoir. This safety requirement has been implemented in Switzerland where average inflows into reservoirs are moderate.

The need for lowering the reservoir was demonstrated during the Wenchuan earthquake in China, where the concrete face of the $156 \mathrm{~m}$ high Zipingpu concrete face rockfill dam was damaged and had to be repaired. Such repairs would be very difficult to perform under water.

Also if the power plant is shut down for long periods of time and due to limitations in the discharge capacity of low level outlets, the spillway may be the only way to control the reservoir level.

In the emergency planning concept it is assumed that every dam can fail or be destroyed. Therefore, the consequences of a dam failure, which is a flood wave caused by the uncontrolled release of the water from the reservoir, must be analysed.

Numerous dam failure scenarios could be considered, however, the main objective of emergency planning is to save lives, therefore, for alarming and evacuating people one has to focus on the worst scenarios with the largest consequences. No failure probabilities are considered for these scenarios. The worst scenario is the instantaneous failure of a dam with full reservoir, which may be due to military action. But also extreme flood events with overtopping of the dam and extreme water levels in the river downstream of the dam may be an extreme scenario as the water stored in the reservoir would be larger than the normal operation level to be considered in the case of instantaneous failure.

Emergency Action Plans (EAP) are intended to help the dam owner and operator, and the emergency officials to minimize the consequences of flooding caused by dam failure or the uncontrolled release of water from a reservoir. The EAP will guide the responsible personnel in identifying, monitoring, responding to, and mitigating emergency situations. It outlines "who does what, where, when, and how" in an emergency situation or unusual occurrence affecting the safety of the dam and the power plant. The EAP should be updated regularly and after important emergency events. Basically, the dam owner is responsible for maintaining a safe dam by means of safety monitoring, operations manual, maintenance, repair, and rehabilitation.

In an emergency situation, the dam owner is responsible for monitoring, determining appropriate alarm levels, making notifications, implementing emergency 
actions at the dam, determining when an emergency situation no longer exists, and documenting all activities. In the case of an emergency, the dam owner is responsible for immediate notification of the authorities, who are in charge of warning and evacuation of the affected population.

Warning is performed by special water alarm systems. The basis for evacuation planning is a dam breach flood wave analysis, which shows the inundated area for the worst-case failure scenario, i.e. the sudden failure of the dam. In addition, the arrival time of the flood wave, flow velocities and water depth are results obtained from such an analysis.

In Switzerland 65 large dams are equipped with a fully functional water alarm system. The first alarm systems were installed over 50 years ago as a consequence of the severe damage of two dams in Germany in 1943, which caused large numbers of casualties. Fortunately up to now these water alarm systems have never had to be used.

\subsubsection{Consequences of Dam Failure and Risk Mitigating Measures}

The consequences of dam failure are: loss of life and injuries (reduction of loss of life is the top priority of emergency planning); environmental damage; property damage in flood plain; damage of infrastructure; loss of power plant and electricity production; socio-economic impact; political impact, etc.

These consequences can be reduced by a number of structural and non-structural measures. The structural measures are mainly related to the safety of the dam, i.e. flood safety, earthquake safety, and site-specific and project-specific safety aspects. The non-structural measures include the following: safe operational guidelines for reservoir under normal and abnormal operational conditions; implementation of emergency action plans; implementation of water alarm systems; training of personnel; lowering of reservoir level in case of safety concerns; periodic safety checks; engineering back-up to cope effectively with abnormal and emergency situations; land use planning (political decision); insurance coverage, third party liability coverage (protection from economic losses), etc. The non-structural measures are often more effective than structural measures.

\subsection{Hazards to Be Considered in Large Dam Projects}

In the design of large dams all possible hazards affecting the project must be considered. A list of typical hazards is given in Table 20.1 (Wieland and Mueller 2009). A distinction can be made between hazards from the natural environment, structural or project-specific hazards, and man-made hazards. In the matrix shown 
Table 20.1 Example of hazard matrix for hydropower plant showing hazards and required protective measures (Emergency classification: A: internal alert; B: developing situation; C: imminent situation)

\begin{tabular}{|c|c|c|c|c|c|}
\hline \multirow[b]{2}{*}{$\underline{\text { Hazards }}$} & \multicolumn{5}{|c|}{ Protective measures } \\
\hline & Rehabilitation & $\begin{array}{l}\text { Partial } \\
\text { reservoir } \\
\text { drawdown } \\
\end{array}$ & $\begin{array}{l}\text { Full } \\
\text { reservoir } \\
\text { drawdown } \\
\end{array}$ & Evacuation & $\begin{array}{l}\text { Post-event } \\
\text { evacuation } \\
\end{array}$ \\
\hline \multicolumn{6}{|l|}{ Natural hazards } \\
\hline Floods & A & $\mathrm{B}$ & & $\mathrm{C}$ & \\
\hline Earthquake & & & & & $\mathrm{C}$ \\
\hline $\begin{array}{l}\text { Mass movements (landslides, } \\
\text { rockfalls, avalanches, etc.) }\end{array}$ & A & $\mathrm{B}$ & & & \\
\hline $\begin{array}{l}\text { Extreme weather conditions } \\
\text { (storm, rainfall, low tem- } \\
\text { peratures, ice, etc.) }\end{array}$ & A & & & & \\
\hline \multicolumn{6}{|l|}{ Structural hazards } \\
\hline $\begin{array}{l}\text { Blockage of spillway gates } \\
\text { (floating debris, pier or gate } \\
\text { deformations, lack of main- } \\
\text { tenance), equipment failure, } \\
\text { power supply, etc. }\end{array}$ & & & $\mathrm{C}$ & $\mathrm{C}$ & \\
\hline $\begin{array}{l}\text { Differential movement of } \\
\text { structure (structural joints, } \\
\text { interfaces between concrete } \\
\text { structures and embank- } \\
\text { ments etc.) }\end{array}$ & A & $\mathrm{B}$ & $\mathrm{C}$ & $\mathrm{C}$ & \\
\hline Embankment piping or seepage & & $\mathrm{B}$ & $\mathrm{C}$ & & \\
\hline $\begin{array}{l}\text { Foundation seepage (damaged } \\
\text { grout curtain, dissolution of } \\
\text { minerals, etc.) }\end{array}$ & A & & & & \\
\hline $\begin{array}{l}\text { Electrical or mechanical failure } \\
\text { of equipment used for } \\
\text { operation of vital gates and } \\
\text { valves (gantry cranes on top } \\
\text { of spillways etc.), failure of } \\
\text { control units, faulty soft- } \\
\text { ware, etc. }\end{array}$ & A & & & & \\
\hline $\begin{array}{l}\text { Ageing, alkali-aggregate reac- } \\
\text { tions etc. }\end{array}$ & A & & & & \\
\hline Man-made hazards & & & & & \\
\hline $\begin{array}{l}\text { Design errors, poor } \\
\text { construction }\end{array}$ & A & & & & \\
\hline $\begin{array}{l}\text { Faulty operation of equipment, } \\
\text { inadequate rule curves for } \\
\text { reservoir operation etc. }\end{array}$ & $\mathrm{A}$ & & & & \\
\hline Sabotage, terrorism, acts of war & & B & & & $\mathrm{C}$ \\
\hline $\begin{array}{l}\text { Other hazards or unknown } \\
\text { hazards (protective mea- } \\
\text { sures depend on the type of } \\
\text { hazard) }\end{array}$ & (A) & (B) & (C) & (C) & (C) \\
\hline
\end{tabular}


also the possible protective measures are given if such hazards develop or events have happened. The protective measures include the following:

(i) Rehabilitation,

(ii) Partial reservoir drawdown,

(iii) Full reservoir drawdown,

(iv) Evacuation, and

(v) Post-event evacuation.

In the emergency classification a distinction is made between internal alert, developing situation, and imminent situation. If unusual behaviour of a dam is observed and if there is adequate time or if safety criteria have changed then rehabilitation of the dam may be required.

In case of a potentially dangerous situation a partial reservoir drawdown may be required.

Finally, in the case of an imminent situation when the hazard cannot be controlled and depending on the available time a full reservoir drawdown, evacuation or in the worst case post-event evacuation and rescue may be needed.

It is obvious from Table 20.1 that the most difficult hazards to handle are those where only post-event evacuation is possible as in the case of a dam failure caused by a strong earthquake or acts of war, terrorism or sabotage. As earthquake prediction is not an option for large dams, the dams must be structurally safe to resist the different features of the seismic hazard. Therefore, the earthquake hazard plays an important role in the design of large dams.

It should be added that in Switzerland the large storage dams had to be designed for specific scenarios of acts of war similar to those, which had led to the breach of the two dams in Germany in World War II. As a consequence the crest thickness of the largest concrete arch and gravity dams is generally larger than that of similar dams in countries, where such scenarios have not been taken into account and certain types of dams, whose reservoirs could not be lowered in a short period of time, such as buttress dams or hollow gravity dams were not permitted. Today this requirement is no longer needed. But a thick dam crest is certainly beneficial for the earthquake safety of both concrete and embankment dams.

\subsection{Earthquakes Create Multiple Hazards in Large Dam Projects}

We have to recognize that the earthquake hazard is a multi-hazard, which may affect large storage dams in different ways (Wieland and Chen 2009):

(i) ground shaking causing vibrations in dams, appurtenant structures and equipment, and their foundations (Fig. 20.1);

(ii) fault movements in the dam foundation or movements along discontinuities in dam foundation near major faults, which can be activated during strong earthquakes, causing structural distortions (Fig. 20.2); 

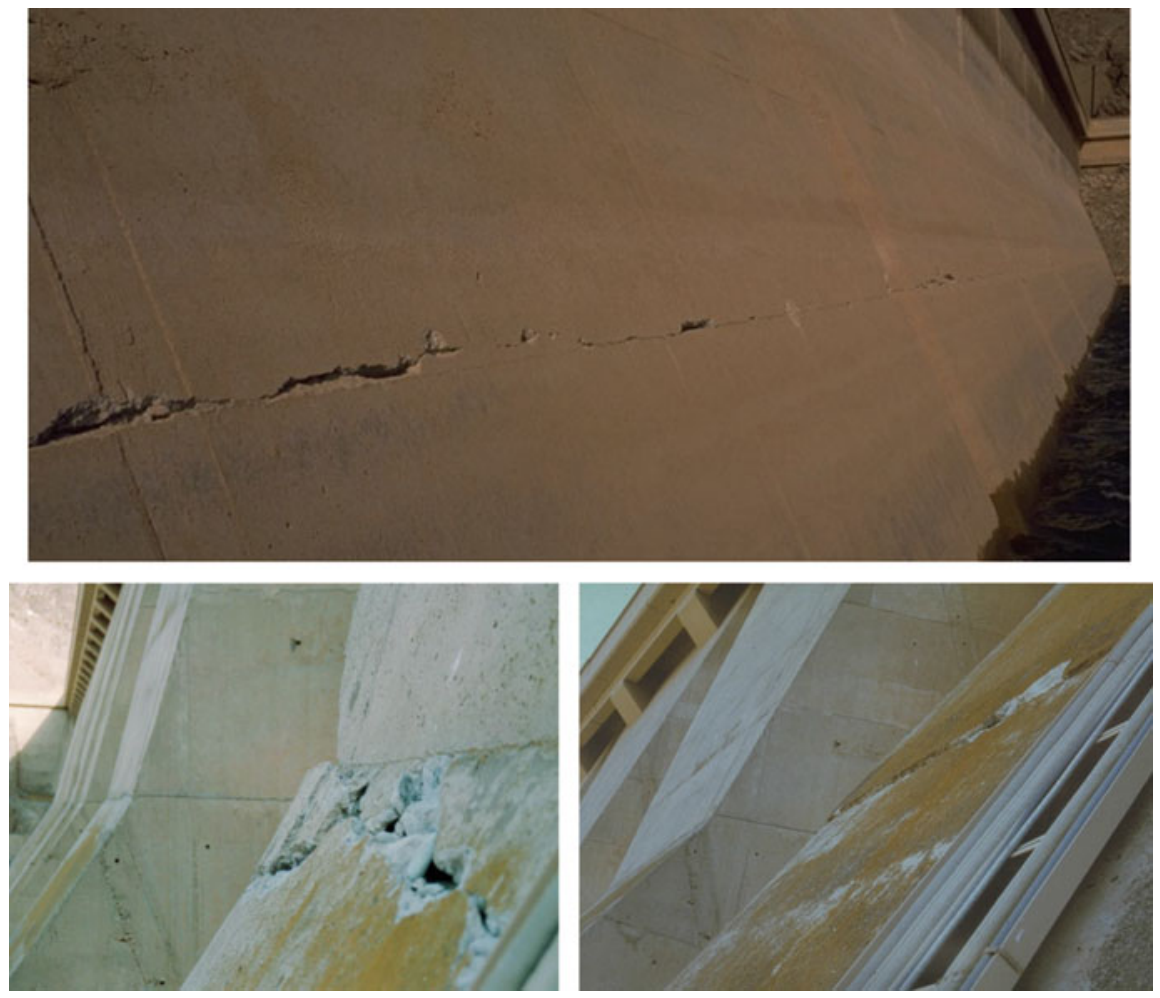

Fig. 20.1 Crack at upstream face (top) and at the kink (left bottom) and crack showing sliding movement of wedge formed by cracks at the kink (right bottom) of the buttress at the downstream face of the Sefid Rud buttress dam caused by ground shaking during the 1990 Manjil earthquake in Iran

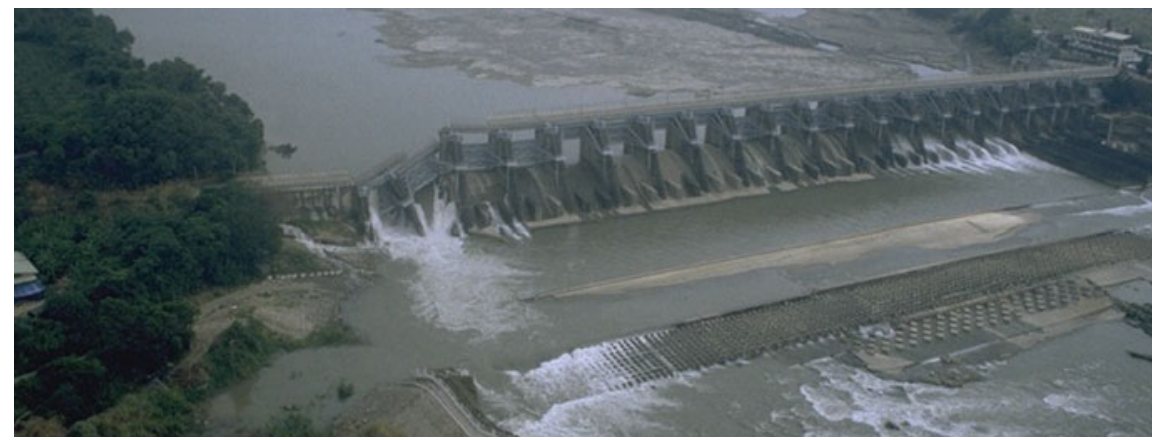

Fig. 20.2 Failure of two openings of the Shih-Kang weir caused by fault movements during the 1999 Chi-Chi earthquake in Taiwan 


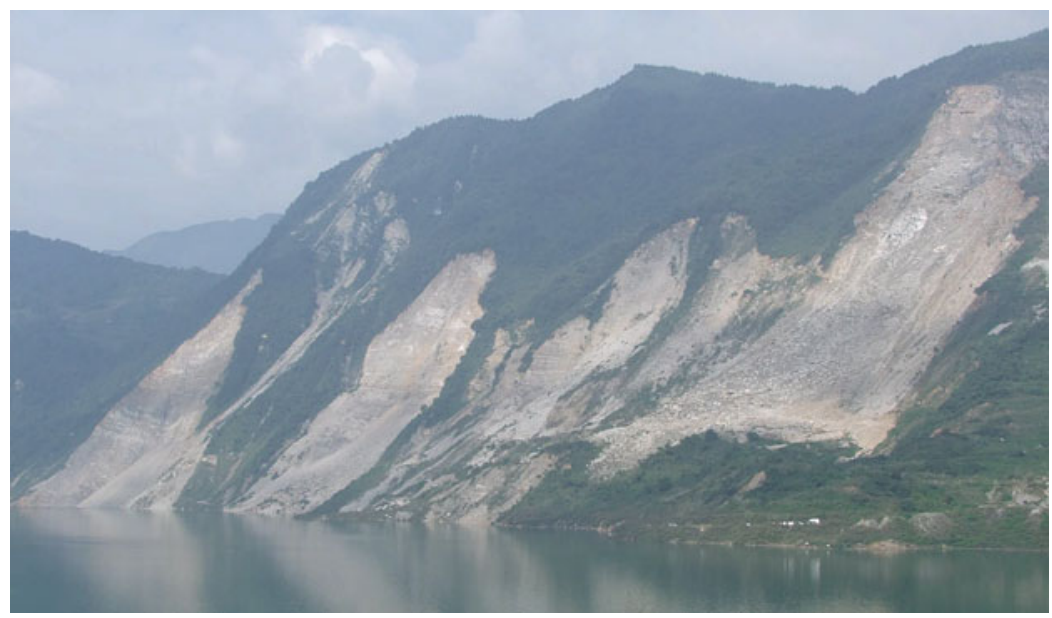

Fig. 20.3 Rockfalls in the Zipingpu reservoir area caused by the 2008 Wenchuan earthquake in China
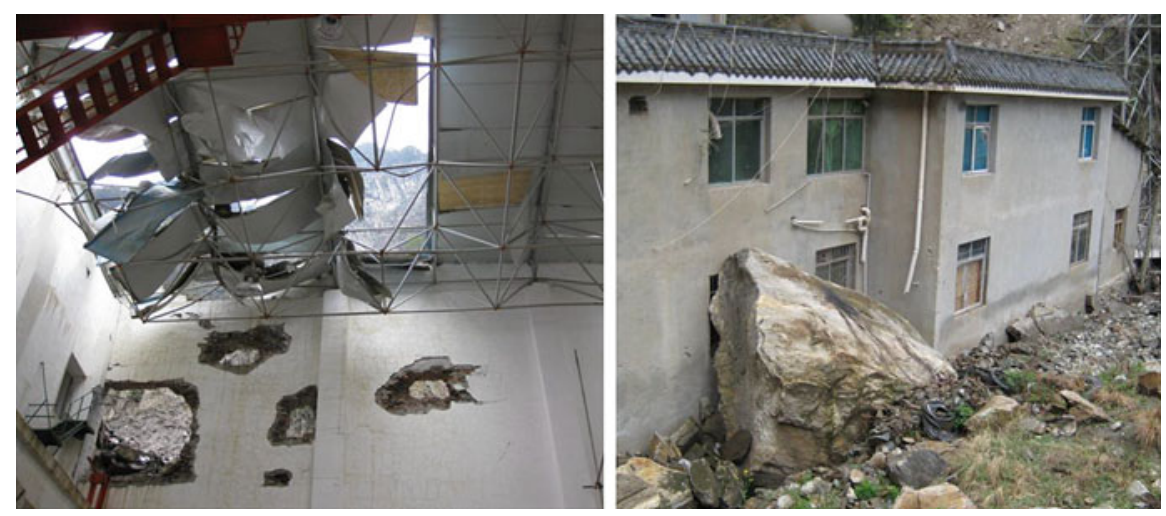

Fig. 20.4 Infill wall and roof of powerhouse punctured by high-velocity rocks (left) and wall damage of building of Shapai power plant by large rock (right) caused by 2008 Wenchuan earthquake

(iii) fault movements in the reservoir causing water waves in the reservoir or loss of freeboard;

(iv) mass movements (rockfalls with large rocks) (Fig. 20.3), causing damage to surface powerhouses (Fig. 20.4), electro-mechanical equipment, gates, spillway piers (Fig. 20.5), retaining walls, penstocks, masts of transmission lines, etc.

(v) mass movements into the reservoir causing impulse waves in the reservoir (Fig. 20.3); 

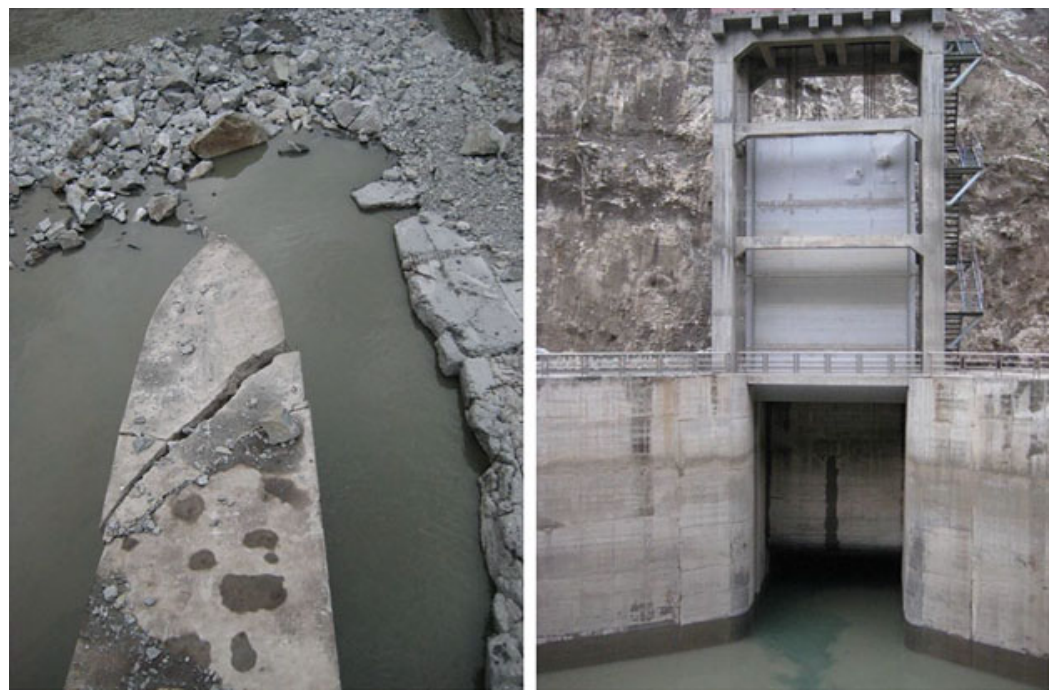

Fig. 20.5 Damaged pier of Futan weir looking downstream (left) and damage of sliding gate for power intake (indentation of steel leaf from rockfall) (right) caused by the 2008 Wenchuan earthquake in China
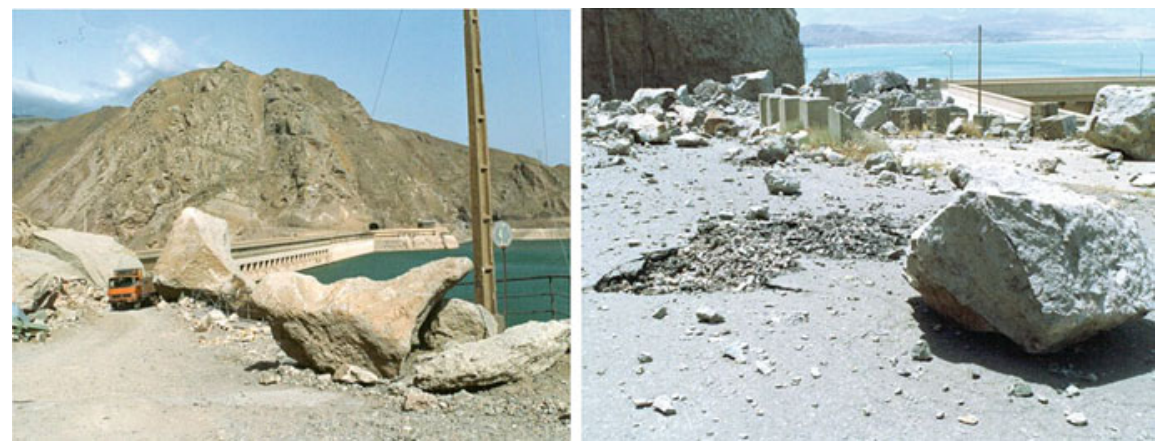

Fig. 20.6 Access roads to Sefid Rud dam site blocked by numerous rockfalls caused by the 1990 Manjil earthquake in Iran

(vi) mass movements blocking rivers and forming landslide dams and lakes whose failure may lead to overtopping of run-of-river power plants or the inundation of powerhouses with equipment;

(vii) mass movements blocking access roads to dam sites and appurtenant structures (Fig. 20.6);

(viii) ground movements and settlements due to liquefaction and densification of soil, causing distortions in dams; and

(ix) turbidity currents in reservoir blocking bottom outlets, power intakes and low level outlets. 
Other seismic hazards such as surface water waves in reservoirs are of lesser importance for the earthquake safety of a dam as their dominant frequencies are much lower than the lowest eigenfrequencies of dams, i.e. the corresponding loads are of quasi static nature, and the maximum amplitude of surface water waves observed during strong ground shaking is less than $1 \mathrm{~m}$.

Usually, the main hazard, which is addressed in codes and regulations, is the earthquake ground shaking. It causes stresses, deformations, cracking, sliding, overturning, etc.

An important hazard, which has generally been underestimated, is the rockfall hazard in mountainous regions.

During the 2008 Wenchuan earthquake, some 30 major landslide lakes were created. Tangjiashan landslide dam with a height of $124 \mathrm{~m}$ with a volume of about $20 \mathrm{Mm}^{3}$, created a reservoir with a volume of $320 \mathrm{Mm}^{3}$, threatening people living downstream of this natural dam.

Every time a strong earthquake occurs, the design guidelines have to be reviewed as new phenomena appear, which may have been overlooked. For example, during the Wenchuan earthquake, the problems of mass movements (mainly rockfalls in steep mountains) and landslide lakes have shown to be very important new features of strong earthquakes. In addition, an unprecedented large number of dams and run-of-river power plants have been affected by this earthquake. The Wenchuan earthquake has confirmed and demonstrated that dams, spillways and appurtenant structures must be able to withstand the multiple effects of strong earthquakes.

\subsection{Seismic Design Criteria for Large Dams and Appurtenant Structures}

The following design earthquakes are needed for the seismic design of the different structures and elements of a large dam project (ICOLD 2014; Wieland 2012a):

(i) Safety Evaluation Earthquake (SEE): The SEE is the earthquake ground motion a dam must be able to resist without uncontrolled release of the reservoir. The SEE is the governing earthquake ground motion for the safety assessment and seismic design of the dam and safety-relevant components, which have to be functioning after the SEE.

(ii) Design Basis Earthquake (DBE): The DBE with a return period of 475 years is the reference design earthquake for the appurtenant structures. The DBE ground motion parameters are estimated based on a probabilistic seismic hazard analysis (PSHA). The mean values of the ground motion parameters of the DBE can be taken. (Note: The return period of the DBE may be determined in accordance with the earthquake codes and regulations for buildings and bridges in the project region.) 
(iii) Operating Basis Earthquake (OBE): The OBE may be expected to occur during the lifetime of the dam. No damage or loss of service must happen. It has a probability of occurrence of about $50 \%$ during the service life of 100 years. The return period is taken as 145 years (ICOLD 2014). The OBE ground motion parameters are estimated based on a PSHA. The mean values of the ground motion parameters of the OBE can be taken.

(iv) Construction Earthquake $(\mathrm{CE})$ : The $\mathrm{CE}$ is to be used for the design of temporary structures such as coffer dams and takes into account the service life of the temporary structure. There are different methods to calculate this design earthquake. For the temporary diversion facilities a probability of exceedance of $10 \%$ is assumed for the design life span of the diversion facilities. Alternatively the return period of the $\mathrm{CE}$ of the diversion facilities may be taken as that of the design flood of the river diversion

The SEE ground motion can be obtained from a probabilistic and/or a deterministic seismic hazard analysis, i.e.

- Maximum Credible Earthquake (MCE): The MCE is the event, which produces the largest ground motion expected at the dam site on the basis of the seismic history and the seismotectonic setup in the region. It is estimated based on deterministic earthquake scenarios. According to ICOLD (2014) the ground motion parameters of the MCE shall be taken as the 84 percentiles (mean plus one standard deviation).

- Maximum Design Earthquake (MDE): For large dams the return period of the MDE is taken as 10,000 years. For dams with small or limited damage potential shorter return periods can be specified. The MDE ground motion parameters are estimated based on a probabilistic seismic hazard analysis (PSHA). According to ICOLD (2014) the mean values of the ground motion parameters of the MDE shall be taken. In the case where a single seismic source (fault) contributes mainly to the seismic hazard, uniform hazard spectra can be used for the seismic design. Otherwise, based on the deaggregation of the seismic hazard (magnitude versus focal distance) different scenario earthquakes may be defined.

For major dams the SEE can be taken either as the MCE or MDE ground motions. Usually the most unfavourable ground motion parameters of these two earthquakes have to be taken. If it is not possible to make a realistic assessment of the MCE then the SEE shall be at least equal to the MDE.

MDE, DBE, OBE and CE ground motion parameters are usually determined by a probabilistic approach (mean values of ground motion parameters are recommended), while for the MCE ground motion deterministic earthquake scenarios are used (84 percentile values of ground motion parameters shall be used). However, for the MDE, DBE, OBE and CE also deterministic scenarios may be defined.

The different design earthquakes are characterized by the following seismic parameters: 
- Peak ground acceleration (PGA) of horizontal and vertical earthquake components.

- Acceleration response spectra of horizontal and vertical earthquake components typically for $5 \%$ damping, i.e. uniform hazard spectra for CE, OBE, DBE and MDE obtained from the probabilistic seismic hazard analysis (mean values) and 84 percentile values of acceleration spectra for MCE obtained from the deterministic analysis using different attenuation models.

- Spectrum-matched acceleration time histories for the horizontal and vertical components of the MCE ground motion determined either from a random process or by scaling of recorded earthquake ground motions. The artificially generated acceleration time histories of the horizontal and vertical earthquake components shall be stochastically independent. To account for aftershocks, it is recommended to increase the duration of strong ground shaking.

In case of fault movements, similar estimates are required as for the ground shaking. It appears that it is quite difficult for the dam designer to get quantitative estimates of fault movements for the different types of design earthquakes as the seismic hazard analyses are mainly concerned with ground shaking.

For underground structures where the effects of imposed deformations are more relevant than inertial effects, the displacement ground motion parameters or displacement time histories of the different design earthquakes are also needed.

The best description of the ground motion is by means of the acceleration time histories. They are needed for any nonlinear dynamic analysis of dams and components. It is also expected that inelastic deformations take place under the SEE ground motion. According to ICOLD (2014) the following aspects of the 'design acceleration time history' should be considered:

(i) The three components of the spectrum-matched acceleration time histories must be statistically independent.

(ii) The acceleration time histories of the horizontal earthquake components may be assumed to act in along river and across river directions. No modifications in the horizontal earthquake components are needed if they are applied to other directions.

(iii) The duration of strong ground shaking shall be selected in such a way that aftershocks are also covered, i.e. records with long duration of strong ground shaking shall be selected.

(iv) In the case of dams that are susceptible to damage processes, which are governed by the duration of strong ground shaking such as, e.g., the buildup of pore pressures, earthquake records with long duration of strong ground shaking shall be used.

(v) For the safety check of a dam at least three different earthquakes shall be considered for the SEE ground motion.

The spectrum-matched acceleration time histories with extended duration of strong ground shaking used for the seismic analysis and design of the dams may be quite different from real ones; however, their use will lead to a safe design, although 
this may difficult to understand or accept by seismologists and other experts, who are not familiar with the seismic design of dams.

In this connection it should be mentioned that in the design of any structures including large dams, the designer will use simplified load and analysis models that lead to a safe design, even if the load model does not comply with the real nature of the hazard and this also applies to the earthquake hazard and the earthquake ground motion.

\subsubsection{Reservoir-Triggered Seismicity}

For some dams an additional earthquake load case was defined for reservoirtriggered seismicity (RTS) or reservoir-induced seismicity (RIS), (Note: The term reservoir-induced seismicity, which in the past has often been used, is not correct as reservoirs cannot induce earthquakes, however, they can trigger earthquakes. Therefore the correct technical term, which also properly describes this phenomenon, is reservoir-triggered seismicity.). RTS has been observed in over 100 reservoir in general with a water depth of the reservoir of over $100 \mathrm{~m}$. The largest magnitudes of RTS events reached 6.3, however, in most cases the magnitudes of these shallowfocus events were much smaller. If RTS is possible or expected in a large dam project then the DBE and OBE ground motion parameters should cover those from the assumed RTS scenarios as such events are expected to occur within a few years after the start of the impounding of the reservoir (ICOLD 2011).

\subsection{Seismic Performance Criteria for Large Dams and Appurtenant Structures}

The rather general performance criteria for the dam body and safety-relevant components and equipment given in ICOLD Bulletin 148 (2014) can be interpreted as follows:

- Performance of dam body during OBE: No structural damage (cracks, deformations, leakage etc.), which affect the operation of the dam and the reservoir, is permitted. Minor repairable damage is accepted. (Note: Crack width limitations do not have to be considered for OBE load combinations in reinforced concrete structures.)

- Performance of dam body during SEE: Structural damage (cracks, deformations, leakage etc.) is accepted as long as the stability of the dam is ensured and no large quantities of water are released from the reservoir causing flooding in the downstream region of the dam. 
- Performance of safety-relevant components and equipment during and after OBE: These components and equipment shall be fully operable after the OBE and therefore should behave elastically during the OBE.

- Safety-relevant components and equipment during and after the SEE: These components and equipment must be fully operable after the SEE. Minor distortions and damage (e.g. leakage of seals of gates) are accepted as long as they have no impact on the proper functioning of the components and equipment.

More specific performance criteria may be given for the SEE, e.g. sliding stability safety factors of slopes of greater than 1.0 are required for an SEE with a return period of 2,500 years in Germany. Such requirements may be stricter than those given above as during strong ground shaking sliding movements of slopes can be accepted, i.e. sliding safety factors may temporarily drop to less than one during the earthquake. However, in this case the allowable sliding movements would have to be defined based on engineering judgement and the stability of the slope after the earthquake, which may be reduced due to the build-up of pore pressures, must be guaranteed. For that case the safety factors must be larger than 1 taking into account residual strength parameters (zero cohesion) and the effect of pore pressure. For the sliding stability of gravity dams or powerhouse complexes that retain the reservoir the same criteria apply. The dynamic sliding stability analyses can be done most easily using the Newmark sliding block method. In general the horizontal and vertical earthquake components should be taken into account in two-dimensional models of slopes or gravity structures. The sliding movements depend on (i) the so-called yield acceleration, which is obtained from a pseudo-static stability analysis of the slope or gravity structure and (ii) the duration of ground shaking. Therefore, if sliding movements are important then it is important to use earthquake records with long duration of strong ground shaking as discussed in the previous section.

In China it is also required that water stops in concrete arch dams shall not be damaged during the SEE with a return period of 5,000 years. This requirement is a criterion for specifying water stops in arch dams, which can cope with the maximum contraction joint opening during the SEE. Actually leakage of joints due to damaged water stops could be accepted, however, in dams with large reservoirs where lowering of the reservoir may be difficult, the repair of damaged water stops would have to be done under water.

The safety-relevant components and equipment are bottom outlets (low level outlets) and spillways and all related equipment (mainly gates), motors, hydraulic systems, control panels, power supply, software etc., as it must be possible to regulate and lower the reservoir after the SEE. As the repair of a damaged dam will need time, it is necessary that after an earthquake a moderate flood equal to about the river diversion flood used during dam construction can still be released safely. This may be a lesser problem for concrete dams or run-of-river power plants, where limited overtopping of the crest may be acceptable under extreme circumstances, however, in the case of embankment dams such overtopping cannot be accepted, thus after an earthquake the possibly damaged or partly inoperable 
spillway of an embankment dam must be able to release larger floods than that of a similar concrete dam. After the 2008 Wenchuan earthquake several run-of-river power plants were overtopped as the power plants were shut down mainly due to failure of the electric grid and the spillway gates could not be opened due to failure of the (emergency) power supply. No damage was caused to the overtopped concrete structures, however, mud was deposited, which required extensive cleaning of the equipment and inundated areas after the earthquake.

The main safety criteria for rockfill dams with impervious core for the SEE are as follows:

(i) loss of freeboard, i.e. after the earthquake the reservoir level shall be below the top of the impervious core of the dam,

(ii) internal erosion, i.e. after the earthquake at least $50 \%$ of the initial thickness of the filter and transition zones must be available, and

(iii) the sliding safety factor of slopes (considering build-up of pore pressure and residual strength parameters of embankment materials) shall be larger than 1 after the earthquake.

The second criterion also applies for earth core rockfill dams located on faults or discontinuities in the dam foundation, which can be moving during a strong earthquake. Moreover, at such sites only conservatively designed earth core rockfill dams should be built.

For concrete dams the main seismic safety criteria are as follows:

(i) stability of dam foundation, i.e. stability of wedges in abutments of arch dams and sliding movements of gravity structures along potential sliding surfaces in the dam foundation, and

(ii) sliding and overturning stability of concrete blocks formed by contraction joints and cracks along lift elevations, i.e. concrete blocks close to the crest in the centre of dams experience the highest absolute acceleration response.

We can conclude that after strong earthquakes, the bottom outlet(s) and the spillway gates are operable, so a moderate flood can be released safely after the earthquake. It has to be assumed that the power plant will be shut down and water cannot be released through the power waterways. For controlling the water level in the reservoir after a strong earthquake it is not necessary that all openings of a spillway have to be functional. Therefore, it may be acceptable to focus on the gates that are essential and to strengthen them seismically. The other gates may remain blocked. However, this appears only feasible for concrete structures where limited overtopping may be accepted. 


\subsection{Conceptual and Constructional Requirements for the Seismic Design of Concrete and Embankment Dams}

\subsubsection{Concrete Dams}

There are several design details that are regarded as contributing to a favourable seismic performance of concrete and in particular arch dams (ICOLD 2001):

- Design of a dam shape with symmetrical and anti-symmetrical mode shapes that are excited by along-river and cross-river components of ground shaking, respectively.

- Maintenance of continuous compressive loading along the foundation, by shaping of the foundation, by thickening of the arches towards the abutments (filets) or by a plinth structure to support the dam and transfer load to the foundation.

- Limiting the crest length to height ratio, to assure that the dam carries a substantial portion of the applied seismic forces by arch action, and that non-uniform ground motions excite higher modes and lead to undesired stress concentrations.

- Providing contraction joints with adequate interlocking (shear keys).

- Improving the dynamic resistance and consolidation of the foundation rock by appropriate excavation, grouting etc.

- Provision of well-prepared lift surfaces to maximize bond and tensile strength.

- Increasing the crest width to reduce high dynamic tensile stresses in arch direction in crest region.

- Minimizing unnecessary mass in the upper portion of the dam that does not contribute effectively to the stiffness of the crest.

- Maintenance of low concrete placing temperatures to minimize initial, heatinduced tensile stresses and shrinkage cracking.

- Development and maintenance of a good drainage system.

The structural features, which improve the seismic performance of gravity and buttress dams, are basically the same as that for arch dams. Earthquake observations have shown that a break in slope on the downstream faces of gravity and buttress dams should be avoided to eliminate local stress concentrations and cracking under moderate earthquakes. The webs of buttresses should be sufficiently massive to prevent damage from cross-river earthquake excitations.

The above criteria apply to conventional mass concrete dams. For RCC dams the same criteria apply. However, the high permeability of some RCC dams along the lifts with a typical vertical spacing of about $30 \mathrm{~cm}$ and the resulting pore pressures within the dam have a negative impact on the dynamic sliding stability of concrete blocks near the crest of the dam formed by the contraction joints and a horizontal crack along lift joints. The seismic sliding movements in downstream direction could be reduced by a watertight membrane or impermeable concrete face in the 
critical crest region of the dam. This also applies to conventional gravity dams at sites where strong ground shaking and significant amplification of the dynamic response (absolute acceleration response) in the central crest region is possible. The maximum amplification of the acceleration from the base to the crest during strong earthquakes can reach values of 4-6 for high gravity dams and 6-8 in high arch dams. For less intense ground motions these amplification factors can reach values up to 13 in very high arch dams, which indicates very low damping of these structures. When shear keys are provided in the contraction of gravity dams, the sliding movements of detached concrete blocks in the crest region is restrained. Therefore it would be favourable id some interlock is also provided at the contraction joints of RCC dams.

The main factor, which governs the dynamic response (stresses and deformations) of a concrete dam is damping. Structural damping ratios obtained from forced and ambient vibration tests are surprisingly low, i.e. damping ratios of the lowest modes of vibrations of large arch dams are of the order of 1 to $2 \%$ of critical. In these field measurements the effect of radiation damping in the foundation and the reservoir are already included.

Linear-elastic dynamic interaction analyses of dam-foundation-reservoir systems would suggest damping ratios (structural and radiation damping) of about $10 \%$ for the lowest modes of vibration and even higher values for the higher modes of large concrete dams. Accordingly, the maximum dynamic tensile stresses in an arch dam might be up to 2-3 times smaller when all dynamic interaction effects are considered than those obtained from an analysis with $5 \%$ damping where the reservoir is assumed to be incompressible and the dynamic interaction effects with the foundation are represented by the foundation flexibility only (massless foundation). Unfortunately, there is still a lack of observational evidence, which would justify the use of large damping ratios in seismic analyses of concrete dams.

Moreover, in view of the fact that large concrete dams will exhibit nonlinear behaviour (joint opening and cracking) during the SEE, the linear dam-reservoirfoundation interaction models with analyses in the frequency domain are not applicable. Therefore, in view of the uncertainties in the estimation of the SEE ground motion, it is proposed to use damping ratios of maximum $5 \%$ for large arch dams and not more than $7 \%$ for gravity dams when no other information and data is available.

\subsubsection{Embankment Dams}

The seismic design of embankment dams is based on

(i) conceptual (empirical) criteria, which are mainly based on the observation of the behaviour of embankment dams during strong earthquakes and the behaviour of soils and rockfill under dynamic loadings, and 
(ii) the results of seismic analysis of dams subjected to different types of design earthquakes, i.e. OBE and SEE. Usually several earthquakes must be analysed - at least three.

As a basis for the dynamic analysis, a static analysis that simulates the incremental construction of the dam body and the filling of the reservoir, and if applicable, a seepage analysis must be performed first before the earthquake ground motion can be applied.

The conceptual and constructional criteria for seismic-resistant fill dams are (ICOLD 2001):

- Foundations must be excavated to very dense materials or rock; alternatively the loose foundation materials must be densified, or removed and replaced with highly compacted materials, to guard against liquefaction or strength loss.

- Fill materials, which tend to build up significant pore water pressures during strong shaking must not be used.

- All zones of the embankment must be thoroughly compacted to prevent excessive settlements during an earthquake.

- All embankment dams, and especially homogeneous dams, must have high capacity internal drainage zones to intercept seepage from any transverse cracking caused by earthquakes, and to assure that embankment zones designed to be unsaturated remain so after any event that may have led to cracking.

- Filters must be provided on fractured foundation rock to preclude piping of embankment material into the foundation.

- Wide filter and drain zones must be used.

- The upstream and/or downstream transition zones should be 'self-healing', and of such gradation as to also heal cracking within the core.

- Sufficient freeboard should be provided in order to cover the settlement likely to occur during the earthquake and possible water waves in the reservoir due to mass movements etc.

- Since cracking of the crest is possible, the crest width should be wider than normal to produce longer seepage paths through any transverse cracks that may develop during earthquakes.

One of the most dangerous consequences of the dynamic loading of an embankment dam is the liquefaction of foundations or embankment zones that contain saturated fine-grained cohesionless and/or uncompacted materials.

The dynamic response of an embankment dam during strong ground shaking is governed by the deformational characteristics of the different soil materials. For large storage dams, the earthquake-induced permanent deformations must be calculated. The calculations of the permanent settlement of large rockfill dams based on dynamic analyses are still very approximate, as most of the dynamic soil tests are usually carried out with maximum aggregate size of less than $5 \mathrm{~cm}$. This is a particular problem for rockfill dams and other dams with large rock aggregates and in dams, where the shell materials, containing coarse rock aggregates, have not been compacted at the time of construction. Poorly compacted rockfill may settle 
significantly during strong ground shaking but may well withstand strong earthquakes.

To get information on the dynamic material properties, dynamic direct shear or triaxial tests with large samples are needed. These tests are too costly for most rockfill dams. But as information on the dynamic behaviour of rockfill published in the literature is also scarce, the settlement prediction involves sensitivity analyses and engineering judgment.

At dam sites located on active or potentially active faults or discontinuities in the dam foundation, which can be moving during a strong earthquake, only conservatively designed earth core rockfill dams should be built. This means that in highly seismically active regions where there are doubts about possible movements along discontinuities in the dam foundation, earth core rockfill dams are the proper dam types (ICOLD 1998).

\subsection{Exisiting Dams}

The seismic safety aspects of existing dams is an important issue as most dam codes, regulations, recommendations and guidelines are primarily concerned with the design of new dams (Wieland 2006).

The design of a dam, which was considered as safe at the time it was commissioned may not be safe forever. This may be contradictory to the general opinion of owners and users of most structures. As earthquake engineering is still a relatively young discipline, design criteria, methods of analysis, design concepts etc. may be subject to changes especially when a large dam, designed according to the current state-of-practice, should be damaged during an earthquake. Thus there is a need for periodic checks of the seismic design criteria and the earthquake safety of large dams (and other structures as well), i.e. budgets for periodic seismic safety checks must be considered.

In general, dam owners and operators are reluctant to perform such checks unless there are laws and regulations and a dam safety organization, which has the authority and means to ensure that the rules are followed. In general, a thorough assessment of the design criteria is done when dam owners are applying for a new concession for their project. This may be adequate in the case of concession periods in the range of 30 years, but in some countries the concession periods are much longer such as, e.g. in Switzerland where the concession period for dam projects is 80 years. In this case reviews of the design criteria should be done as discussed in the previous section on Dam Safety Monitoring.

Again, the perception that what has been considered as safe once will remain safe forever is a dangerous misconception.

As a consequence during the long service life of a dam several seismic safety assessments will be needed.

In most European countries the economically feasible water resources have been developed. Although large dams belong to the first structures, which have been 
designed systematically against earthquakes since the 1930s, the seismic safety of these dams is unknown, as most of them have been designed using seismic design criteria and methods of dynamic analysis (pseudo-static analysis method) that are considered obsolete today.

The fact that no major dams have failed during earthquakes and that few lives have been lost may give the impression that well-designed dams are safe against earthquakes. We need to re-evaluate the seismic safety of existing dams based on current state-of-the-art practice and rehabilitate existing dams if necessary.

Additionally, there are a large number of smaller dams, especially earth structures, which were built either for irrigation or water supply by organisations or villagers with little experience in dam construction or they were built in previous centuries and subsequently abandoned. Earthquake effects on these dams have usually not been considered or in rather simplistic way.

As a prerequisite the seismic hazard at the dam sites must be reassessed to comply with the current seismic design criteria.

It must be pointed out that both new and existing large storage dams must satisfy today's safety criteria, which are equal for new and existing dams. Therefore a riskbased approach in which the remaining service life and the acceptable investment cost for saving additional lives is taken into account for existing dams, cannot be recommended.

\subsection{Conclusions}

In the seismic design and seismic safety assessment of the dams the following items are of main concern:

1. The seismic hazard is a multi-hazard for most dam projects. Ground shaking is the main hazard considered in all earthquake guidelines for dams. The other seismic hazards may even have been ignored.

2. Movements of active faults in the foot print of a dam or movements at discontinuities (faults, joints, bedding planes), which can be activated during strong nearby earthquakes, are the most critical seismic hazard for most dam types. If no other site can be selected then a conservatively designed earth core rockfill dam with wide filter and transition zones would be the right solution.

3. Dams are not inherently safe against earthquakes. However, the technology for designing and building dams and appurtenant structures that can safely resist the effects of strong ground shaking is available.

4. The concrete slab of concrete face rockfill dams is vulnerable to seismic settlements and seismic actions causing large inplane stresses if it acts as a monolithic structure. Open joints can almost completely eliminate these stresses resulting from the greatly different deformational behaviour and the great differences in the stiffness of the rockfill and the concrete. 
5. As most dams built prior to 1989 when ICOLD has published its seismic design criteria of dams (ICOLD 2014), have not been checked for the SEE ground motion, the earthquake safety of these dams is not known and it must be assumed that a number of them do not satisfy today's seismic safety criteria. Therefore, owners of older dams shall start with the seismic safety checks of their dams.

6. The earthquake load case has evolved as the critical load case for most large dams even in regions of low to moderate seismicity.

7. Due to changes in the seismic design criteria and the design concepts it may be necessary to perform several seismic safety checks during the long economical life of a large dam.

8. Our knowledge on the behaviour of large dams during strong ground shaking is still very limited, therefore, each destructive earthquake affecting dams may reveal new features, which up to now have been overlooked or ignored.

Acknowledgements The author acknowledges the contributions of the members from the 32 countries participating in the works of the Committee on Seismic Aspects of Dam Design of the International Commission on Large Dams, which were published as ICOLD bulletins.

Open Access This chapter is distributed under the terms of the Creative Commons Attribution Noncommercial License, which permits any noncommercial use, distribution, and reproduction in any medium, provided the original author(s) and source are credited.

\section{References}

ICOLD (1998) Neotectonics and dams, bulletin 112, Committee on Seismic Aspects of Dam Design, International Commission on Large Dams (ICOLD), Paris

ICOLD (2001) Design features of dams to effectively resist seismic ground motion, bulletin 120, Committee on Seismic Aspects of Dam Design, International Commission on Large Dams (ICOLD), Paris

ICOLD (2011) Reservoirs and seismicity - state of knowledge, bulletin 137, Committee on Seismic Aspects of Dam Design, International Commission on Large Dams, International Commission on Large Dams (ICOLD), Paris

ICOLD (2014) Selecting seismic parameters for large dams, guidelines, bulletin 148, Committee on Seismic Aspects of Dam Design, International Commission on Large Dams (ICOLD), Paris

Wieland M (2003) Seismic aspects of dams, general report, Q.83 seismic aspects of dams. In: Proceedings of 21st international congress on large dams, ICOLD, Montreal

Wieland M (2006) Earthquake safety of existing dams, keynote lecture. In: Proceedings of first European conference on earthquake engineering and seismology, 1ECEES, (a joint event of the 13th European Conference on Earthquake Engineering \& 30th General Assembly of the European Seismological Commission), Geneva, 3-8 Sept

Wieland M (2012a) Seismic design and performance criteria for large storage dams. In: Proceedings of 15th world conference on earthquake engineering, Lisbon, 24-28 Sep

Wieland M (2012b) Safety aspects of sustainable storage dams. In: Proceedings of 3rd International Symposium on Life-Cycle Civil Engineering (IALCCE 2012), Mini-symposium on sustainable dams and embankments, Vienna, 3-6 Oct

Wieland M, Chen H (2009) Lessons learnt from the Wenchuan earthquake. Int Water Pow Dam Constr 61(9):36-40

Wieland M, Mueller R (2009) Dam safety, emergency action plans, and water alarm systems. Int Water Pow Dam Constr 61:34-38 